\title{
Repercussões da Aposentadoria na Dinâmica Relacional Familiar na Perspectiva do Casal
}

\author{
Marcos Henrique Antunes \\ Dulce Helena Penna Soares \\ Carmen Leontina Ojeda Ocampo Moré \\ Universidade Federal de Santa Catarina \\ Florianópolis, SC, Brasil
}

\begin{abstract}
RESUMO
Este estudo de natureza qualitativa foi desenvolvido com o objetivo de compreender as repercussões da aposentadoria na dinâmica relacional familiar na perspectiva do casal. Participaram da pesquisa 06 casais aposentados com estrutura familiar composta pelos subsistemas conjugal/parental e fraternal/filhos. Os dados foram coletados por meio de entrevistas semiestruturadas, sendo os mesmos analisados, organizados e integrados em categorias, seguindo os princípios da Grounded Theory. Os resultados evidenciaram que a aposentadoria é um estressor no ciclo vital da família, visto que a iminência deste período ocasiona a reorganização do sistema familiar, afetando os padrões comportamentais e a qualidade dos vínculos estabelecidos entre o casal e destes com seus filhos. Ressalta-se a importância de considerar as regras implícitas e explícitas que foram construídas ao longo dos anos de convívio, pois essa tarefa se constitui um desafio para a família nessa etapa do ciclo vital.
\end{abstract}

Palavras-chave: Aposentadoria; família; relações familiares; relações conjugais.

\section{ABSTRACT}

\section{Effects of Retirement in Relational Dynamics in the Families: A Perspective of Couples}

This qualitative study was developed with the objective of understanding the repercussions of retirements in relational dynamics in the families, from the perspective of couples. Six retired couples have participated in this study, with family structures composed by the parental/conjugal and fraternal/children subsystems. The data of this research were collected through semi-structured interviews, which have been analyzed, organized, and integrated, into categories following Grounded Theory principles. Results show that retirement is a stress factor in the family life cycle, as the imminence of this period reorganizes the family system, affecting behaviour patterns and the quality of bonds established among the couple, and between the couple and their children. Highlights the importance of considering the implicit and explicit rules built through years, as this task constitutes a challenge for the family in this stage of their life cycle.

Keywords: Retirement; family; family relations; marital relations.

\section{RESUMEN}

\section{Repercusiones de la Jubilación en la Dinámica Relacional Familiar en la Perspectiva de la Pareja}

Este estudio cualitativo fue desarrollado con el objetivo de comprender las repercusiones de la jubilación en la dinámica relacional familiar en la perspectiva de la pareja. Los participantes fueron 06 parejas jubiladas con estructura familiar compuesta por subsistemas conyugal/de los padres y fraterno/hijos. Los datos fueron recolectados a través de entrevistas semi-estructuradas, siendo que los mismos fueron analizados, organizados y integrados en categorías, siguiendo los principios de la Grounded Theory. Los resultados muestran que la jubilación es un factor de estrés en el ciclo de vida de la familia y la inminencia de este periodo conduce a la reorganización del sistema familiar, afectando las normas de comportamiento y la calidad de los vínculos que se establecen entre la pareja y éstos con sus hijos. Se concluye sobre la importancia de considerar las reglas implícitas y explicitas que se han construido a través de los anos de convivio, porque esta tarea es un desafío para la familia en esta etapa del ciclo de vida.

Palabras claves: Jubilación; familia; relaciones familiares; relaciones conyugales. 


\section{INTRODUÇÃO}

O desligamento laboral é considerado um evento potencialmente estressante e que acarreta significativas mudanças no contexto de vida do indivíduo. Diferentes estudos têm evidenciado que a aposentadoria, enquanto parte deste processo, envolve incertezas, preocupações e ansiedade, constituindo-se um fenômeno complexo, dinâmico e multideterminado (Denton \& Spencer, 2009; França, Menezes, Bendassoli, \& Macedo, 2013; Zanelli, 2012). Para além de um entendimento linear, no qual a aposentadoria significa apenas a passagem do trabalho para a ausência deste ou o recebimento de um benefício previdenciário, julga-se necessário refletir acerca dos múltiplos fatores que estão imbricados em sua apreensão, integrando aspectos históricos, sociais e culturais.

Nos últimos vinte anos, o campo da produção científica, assim como outros espaços da sociedade, têm conferido maior ênfase à discussão deste tema, o que acontece, principalmente, em razão dos desafios que emergem face ao cenário demográfico da população mundial, marcado pelo aumento significativo do índice de longevidade (Johnson, 2009). No Brasil, o último censo demográfico (IBGE, 2011), demonstra que em 2010, a população era de 190,8 milhões, dos quais $42,03 \%$ correspondiam ao grupo etário de pessoas entre 0 e 24 anos de idade, $47,18 \%$ ao grupo entre 25 e 59 anos de idade, e 10,79\% ao grupo com 60 anos ou mais. Analisando que no ano 2000 tais grupos etários correspondiam, respectivamente, a 49,67\%, 41,76\% e $8,56 \%$, denota-se uma progressiva mudança na sua composição ao longo desta década.

Estes dados permitem evidenciar a diminuição constante do grupo jovem e o aumento nos níveis de qualidade de vida e de longevidade, crescimento da população idosa e, consequentemente, do número de aposentados. Ressalta-se, portanto, a importância de discutir sobre as políticas públicas voltadas ao aposentado e à pessoa idosa, bem como acerca do impacto provocado pelo prolongamento do curso de vida, sobretudo, no contexto familiar.

A aposentadoria, comumente, é considerada um recomeço nos diversos âmbitos da vida e os relacionamentos familiares ocupam lugar de destaque nos projetos para este período (Duarte \& Melo-Silva, 2009; França, 2009; Magalhães et al., 2004). Entende-se que o ambiente familiar se configura um dos principais espaços que serão habitados pelo aposentado, no qual ele emprega seu tempo e ação (Zanelli, Silva, \& Soares, 2010). Todavia, esse processo ocasiona desdobramentos nos vínculos e na estrutura da família, exigindo que os seus integrantes avaliem as relações estabelecidas quer seja pelo casal, quer seja pelos pais com seus filhos ou vice-versa (Azevedo \& Carvalho, 2006; Couto et al., 2008; França, Menezes, \& Siqueira, 2012).

O presente estudo, ancorado na perspectiva teórica Sistêmica, compreende a família como um conjunto de pessoas em interação, uma pequena sociedade, que se modifica ao longo do tempo e cujos membros estão em contato, possuem laços emocionais, padrões de interação, crenças, tradições e uma história compartilhada (Carter \& McGoldrick, 1995; Cerveny, 2011; Minuchin, 1982). Nesse sentido, a dinâmica relacional familiar, conforme postula Andolfi (2003), diz respeito a uma apreensão ampla do sistema, em termos de como a família se constitui, como os diferentes membros interagem entre si e com outros sistemas, quais são as pautas que estabelecem os padrões relacionais embasadas nos valores, mitos, segredos, rituais e outros aspectos transmitidos entre as gerações.

O relacionamento entre os componentes da família se organiza por meio de estágios distintos, e, embora haja uma interdependência entre as fases e as transições experimentadas em cada família, não há um formato linear capaz de representar esse processo. $\mathrm{O}$ ciclo de vida familiar, conforme proposto por Carter e McGoldrick (1995), introduz uma perspectiva do desenvolvimento humano interligado e concomitante ao desenvolvimento familiar. As transições familiares são experimentadas de diferentes maneiras em cada indivíduo e em cada geração, de modo que, esses pontos de passagem de um estágio do ciclo de vida para outro são geradores de estresse nos familiares, especialmente por demandarem adaptação à nova realidade que se apresenta (Andolfi, 2003; Carter \& McGoldrick, 1995; Walsh, 1995).

Apesar da relevância dessa discussão, verificou-se que a produção científica que versa sobre a interface entre aposentadoria e família é uma prática recente e pode ser encontrada, preponderantemente, na literatura internacional (Antunes \& Moré, 2014; Szinovacz et al., 2012). Esse apontamento se comprova, também, pela escassez de publicações em livros e por não haver linhas de pesquisas cadastradas no Diretório dos Grupos de Pesquisas do CNPq com essa problemática explícita em sua descrição. Para Szinovacz (2003), a lacuna na produção científica que se preocupa em aprofundar o entendimento das implicações sobre estes domínios pode ser particularmente problemática, posto que a família é um dos principais espaços que serão habitados pelo indivíduo aposentado e, com frequência, motivo de apreensão acerca dos desdobramentos nos padrões relacionais após a efetivação da aposentadoria. 
Como base no exposto, este estudo foi desenvolvido com o objetivo de compreender as repercussões da aposentadoria na dinâmica relacional familiar na perspectiva de casais aposentados. Os dados apresentados derivam da dissertação de Mestrado defendida pelo primeiro autor sob orientação das demais autoras. Por meio deste estudo, pretendese sensibilizar para a reflexão acerca dos aspectos relacionais imbricados no desligamento laboral, bem como dos desafios da reorganização familiar frente a este evento de ciclo de vida. Acredita-se que os resultados podem subsidiar a intervenção profissional no atendimento à aposentados e familiares.

\section{MÉTODO}

\section{Participantes}

Participaram do estudo 06 casais, totalizando 12 pessoas envolvidas. A estrutura familiar dos participantes estava configurada pelo modelo tradicional, composta pelos subsistemas conjugal/ parental e fraternal/filhos. A idade dos participantes variou entre 56 e 68 anos, sendo a média de 61 anos. Cabe mencionar que o nível de escolaridade variou entre Ensino Técnico e Doutorado e todos residiam em meio urbano.

Em relação às ocupações exercidas por esses indivíduos, constatou-se que, com exceção de um casal no qual a esposa referiu ser "do lar", em todos os demais, ambos os cônjuges desenvolveram carreiras com atividades externas ao ambiente familiar. A renda mensal do casal variou entre 10 e 40 salários mínimos, sendo a média correspondente a 18 salários mínimos vigentes. Acerca do período em que se encontravam aposentados, este variou de 01 ano e meio à 15 anos, cuja média é de 05 anos. Observou-se que as participantes mulheres estavam aposentadas há mais tempo que seus maridos, sendo que duas delas mencionaram não receber nenhum tipo de benefício.

A respeito da constituição familiar destes casais, foi verificado que todos possuiam filhos, cujo número variou entre 01 e 02 filhos, com idades entre 24 e 36 anos, ficando a média em 30 anos. Reitera-se que, do total de 06 casais, 02 deles ainda convivem com os filhos na residência da família, os quais dependem dos pais, inclusive, financeiramente.

\section{Instrumentos}

A coleta de dados foi realizada por meio de entrevistas semiestruturadas, cujo roteiro era composto por: a) dados sócio-demográficos e de identificação, b) questões norteadoras referentes à experiência de aposentadoria, c) questões específicas em relação às implicações da aposentadoria no contexto familiar.

\section{Procedimentos}

Acerca dos preceitos éticos, todos os procedimentos relativos ao desenvolvimento deste estudo foram orientados pelas regras de pesquisa com seres humanos, conforme disposto na Resolução 196/1996 (Brasil, 1996). O parecer favorável para execução da pesquisa foi emitido pela Instituição de Ensino na qual os autores estão vinculados, sob o n ${ }^{\circ}$ 313.979.

Para acesso e convite aos participantes da pesquisa foi utilizada a técnica Bola de Neve (Denzin \& Lincoln, 2000), de modo que o contato com eles ocorreu intermediado pelas indicações das redes de relações pessoais dos pesquisadores e do grupo de pesquisa ao qual pertencem. O primeiro contato com os casais foi estabelecido via telefone, sendo que, nesse momento, eles eram informados sobre os objetivos da pesquisa e convidados para participar dela, além de proceder-se a verificação dos critérios estabelecidos para a mesma.

A coleta de dados aconteceu nas residências dos participantes e foi realizada pelo primeiro autor. Antes de iniciar as entrevistas, o pesquisador voltava a esclarecer sobre os objetivos da pesquisa e verificava o interesse dos indivíduos em participar do estudo e conceder informações sobre sua trajetória pessoal. A partir disto, era realizada a leitura e assinatura do Termo de Consentimento Livre e Esclarecido.

As entrevistas semiestruturadas foram conduzidas individualmente, ou seja, em momentos distintos com cada um dos cônjuges. Os dados coletados foram gravados mediante a autorização dos participantes, e, posteriormente, transcritos.

\section{Análise dos dados}

Os dados foram organizados e analisados qualitativamente por meio do método da Grounded Theory, desenvolvida por Strauss e Corbin (2008). O processo de análise dos dados envolveu as seguintes etapas: a) interação com os dados por meio de leituras sucessivas do material coletado; b) codificação aberta, na qual os dados foram examinados, desmembrados e, posteriormente, agrupados; c) criação das categorias, as quais foram nomeadas de acordo com os aspectos nucleares evidenciados e a representação dos códigos tal como foram agrupados; d) codificação axial, sendo este o processo de estabelecer subcategorias e elementos de análise a serem abordados em cada uma das categorias; e) fenômeno central, o qual se refere à triangulação entre os dados coletados e a literatura, sendo possível sustentar a compreensão do fenômeno investigado neste estudo. 
O conjunto de dados obtidos a partir da coleta de dados possibilitou a elaboração de duas categorias de análise com suas respectivas subcategorias. A primeira delas, denominada "As mudanças no contexto familiar no processo de aposentadoria", congrega as subcategorias: a) sobre a organização da família no período em que os cônjuges ainda estavam trabalhando, b) sobre a organização da família após a aposentadoria, c) sobre o relacionamento conjugal após a aposentadoria, d) sobre o relacionamento com os filhos após a aposentadoria. Por sua vez, a segunda categoria, intitulada "O tensionamento do ciclo de vida familiar no processo de aposentadoria", reúne as seguintes subcategorias: a) as tarefas relacionadas ao ciclo de vida familiar no período de aposentadoria, b) as funções desempenhadas pela família na aposentadoria, c) aspectos que interferem na adaptação à aposentadoria. Cabe mencionar que essa organização pretende demonstrar a singularidade das vivências descritas pelos participantes em torno do fenômeno de estudo.

\section{RESULTADOS E DISCUSSÃO}

\section{As mudanças no contexto familiar no processo de aposentadoria}

Nesta categoria são abordados aspectos da estrutura e do funcionamento familiar em dois momentos: o primeiro deles se refere ao período em que ambos os cônjuges permaneciam trabalhando, e, o segundo, à aposentadoria. Ademais, são destacadas as modificações que ocorrem nos relacionamentos conjugal e parental nesse processo.

A primeira subcategoria, denominada "Sobre a organização da família no período em que ainda trabalhavam", trata de aspectos em torno do funcionamento e dos vínculos afetivos presentes na dinâmica relacional familiar no momento em que os cônjuges ainda encontravam-se envolvidos nas atividades laborais. Nesses termos, verificaram-se duas realidades em torno do modo pelo qual acontecia a participação e o desempenho de tarefas entre homens e mulheres. A primeira delas retrata uma divisão sexista, que conferia às mulheres um lugar central no cumprimento das demandas familiares. Percebeu-se que tais atividades eram executadas simultaneamente aos compromissos profissionais ou, ainda, ocasionaram o abandono destes. Nesses casos, as mulheres mantinham sobre si as principais funções a serem desempenhadas e os homens estavam mais liberados das obrigações com a família, e, assim, podiam se dedicar integralmente ao trabalho.

A segunda realidade, descrita por três participantes, retrata o equilíbrio na divisão das tarefas familiares.
Essa condição possibilitava o envolvimento de ambos os cônjuges tanto nas atividades profissionais quanto nas familiares, o que, inclusive, favorecia a proximidade e a convivência do casal. Observou-se que, nesse contexto, as tarefas eram desenvolvidas a título de cooperação entre os cônjuges, não havendo hierarquia ou definição rígida dos papéis a serem desempenhados por eles.

Os dados provocaram a reflexão em torno das diferenças de gênero que são estabelecidas culturalmente e atribuem diferentes papéis a serem cumpridos pelas pessoas nas suas respectivas famílias. Considera-se que a perspectiva sexista é capaz de gerar acordos que não são explícitos no casal, os quais determinam expectativas e padrões de comportamento, bem como as particularidades do funcionamento familiar. Contudo, é importante destacar que as configurações familiares contemporâneas têm apresentado uma ampliação da participação dos homens nas questões familiares e, principalmente, na função parental, indo ao encontro do que foi discutido por Amazonas, Vieira e Pinto (2011). Nessas condições, a organização da família possibilita aos seus membros uma maior autonomia no cumprimento dos papéis, de modo que as responsabilidades não permaneçam concentradas ou, ainda, sobrecarregando apenas um indivíduo.

A segunda subcategoria "Sobre a organização da família após a aposentadoria", apresenta aspectos que retratam as modificações transcorridas no funcionamento familiar mediante o cessamento das atividades laborais. Seis participantes relataram mudanças em suas rotinas, tendo em vista que, ao terem se afastado do trabalho, a forma de organização de suas vidas sofreu mudanças significativas e as atividades desenvolvidas foram dispostas de uma maneira diferente da qual eram cumpridas anteriormente. Observou-se que este processo não ocorreu de modo linear, mas demandou que eles tomassem decisões em relação às atividades que pretendiam desempenhar em sua aposentadoria, o que resultou em uma reorganização dos seus estilos de vida. A pesquisa de Magalhães et al. (2004) se aproxima desta realidade ao mostrar as transformações que ocorrem na aposentadoria, cujo ajustamento envolve diferentes possibilidades e está relacionado à habilidade do indivíduo de negociar e efetivar redefinições dos papéis cumpridos.

Além disso, verificou-se que a percepção das mudanças vai além da perspectiva individual e diz respeito, também, ao estágio do ciclo de vida familiar, cabendo destacar que nesse momento alguns participantes não tinham mais a presença dos filhos em casa e as principais demandas estavam direcionadas ao relacionamento conjugal. Os participantes citaram que, 
com a aposentadoria, ocorreu a ampliação da presença e da participação dos cônjuges no ambiente familiar, fato que está de acordo com a pesquisa de Azevedo e Carvalho (2006). Assim, reitera-se que a mudança na rotina não é um elemento isolado do processo de aposentadoria, mas precisa ser ponderada face ao contexto de vida do indivíduo e as particularidades de cada estágio de desenvolvimento familiar.

Observou-se que a aposentadoria do cônjuge também ocasionou mudanças na rotina, seja na vida daquele que já estava aposentado ou na organização familiar. Entretanto, destaca-se que essas vivências foram verificadas no relato das esposas, as quais se aposentaram antes que seus parceiros. Isto ocorre, especialmente, em virtude das normas que regem a Previdência Social, posto que estas preveem que, devido ao quesito da idade, as mulheres tenham a possibilidade de se aposentarem antes dos homens. Nesse sentido, emergiu o seguinte questionamento: em que medida as mulheres casadas são duplamente atingidas pelos desdobramentos da aposentadoria? Isto é, primeiro quando efetivam seu próprio desligamento laboral, e, novamente, quando o marido realiza este movimento.

Identificou-se que as mudanças no cotidiano envolveram todos os membros da família, tendo em vista que os relatos dos cônjuges sinalizaram, inclusive, percepções de estranhamento dos seus filhos, os quais passaram a conviver com a experiência de ter ambos os pais em casa e em tempo integral. Este aspecto coaduna-se com o que foi discutido por Soares et al. (2007), pois, segundo os autores, a aposentadoria ocasiona modificações na rotina dos integrantes da família, sendo necessário repensar a configuração desta para conferir espaço ao aposentado.

Desse modo, foi possível constatar que a mudança na rotina abrange condições tais como a reestruturação do tempo de convivência direta entre os componentes da família, das atividades desenvolvidas e dos espaços ocupados por estes. Com isso, são estabelecidas novas demandas na organização familiar, as quais provocam uma reformulação do cotidiano e dos costumes já estabelecidos (Carter \& McGoldrick, 1995; Couto et al., 2008).

Outro aspecto salientado pelos participantes diz respeito ao compartilhamento de tarefas domésticas, ou seja, o envolvimento de ambos os cônjuges na execução de atividades no contexto familiar. Constatou-se que, no caso dos participantes que já haviam referido uma divisão equilibrada dos afazeres no casal antes da aposentadoria, essa prática parece ter sido ampliada nesse período, contando com um maior envolvimento do marido. Porém, entre os demais, notaram-se ambivalências e dificuldades sobre esse aspecto do funcionamento familiar, sendo que isto foi verificado tanto na fala dos homens quanto das mulheres. Esse fato pode estar relacionado a questões de gênero, expressando possíveis dificuldades em perceber a inserção dos maridos em espaços que, ao longo do tempo, pertenceram à suas esposas, bem como em assumir funções de cuidado com a casa, atividade geralmente atribuída às mulheres.

As narrativas demonstraram que esse processo pode desencadear o tensionamento da relação conjugal, gerando conflitos entre os componentes do casal devido à necessidade de fazer ajustes em sua dinâmica relacional. Isto é, com a efetivação da aposentadoria, ocorreu um redimensionamento das esferas ocupadas pelos cônjuges no sistema familiar. Assim, o tensionamento das relações transcorreu em virtude da transição para uma nova etapa do ciclo de vida, a qual exigiu que os componentes da família desempenhassem papéis diferentes dos habituais. Segundo Carter e McGoldrick (1995), quando o casal se encontra mediante esses momentos de transição, é necessário que os seus componentes façam negociações em torno dos campos de influência e atividade nos quais estão envolvidos, estabelecendo fronteiras que possibilitem a diferenciação entre eles.

No que diz respeito à terceira subcategoria, intitulada "Sobre o relacionamento conjugal após a aposentadoria", dos doze participantes, sete mencionaram uma melhora no relacionamento conjugal após a aposentadoria. Esta percepção estava intrinsecamente relacionada à ampliação do tempo disponível para interagir e realizar atividades em conjunto no casal. Percebeu-se que, na medida em que os cônjuges têm mais possibilidades de voltarem-se para a relação conjugal, é possível ocorrer o fortalecimento de aspectos que não estavam recebendo tanta dedicação e, assim, melhorar a qualidade do seu vínculo. Desse modo, reitera-se o que havia sido apontado por Oliveira e Cerveny (2011). Para as autoras, o relacionamento do casal adquire proeminência nesta fase do ciclo de vida da família, tendo em vista que somam-se condições para que os parceiros possam ressignificar e remodelar a relação.

Evidenciou-se, ainda, a necessidade de os cônjuges estabelecerem os seus campos de inserção na família no período da aposentadoria. Esses espaços devem respeitar tanto os interesses individuais quanto aqueles que são comuns ao casal. Como este é um período do ciclo de vida no qual ocorre uma intensificação da convivência e do contato entre os cônjuges (Couto et al., 2008; Oliveira \& Cerveny, 2011; Soares et al., 2007), levantou-se a hipótese de que as dificuldades 
que podem emergir no relacionamento nesse processo, estejam também associadas às negociações a ser realizadas em torno dos campos e atividades nos quais irão se inserir, de acordo com os anseios apresentados por ambos os cônjuges. Por meio destes dados, é possível inferir que, na medida em que os cônjuges conseguem equilibrar suas demandas individuais e conjugais, adquirem maior liberdade para realizar suas escolhas, o que interfere tanto na adaptação e satisfação à aposentadoria quanto na qualidade da relação conjugal.

$\mathrm{Na}$ quarta subcategoria, nomeada "Sobre o relacionamento com os filhos após a aposentadoria", são discutidos aspectos da relação parental nesse período. Nesses termos, seis participantes descreveram uma aproximação no relacionamento, intermediada pelo aumento na convivência entre pais e filhos. Observou-se que isso ocorre tanto em termos de realizar atividades juntos, quanto pela utilização da tecnologia. Cabe destacar que este aspecto foi apresentado pelos participantes como sendo uma das mudanças satisfatórias que ocorreram após o cessamento das atividades laborais, os quais enfatizaram que, nesse período, as condições para interação se ampliaram significativamente.

Sobre o relacionamento parental após a aposentadoria, foram verificadas diferenças entre os participantes que possuíam filhos financeiramente dependentes e os que possuíam filhos financeiramente independentes. No primeiro caso, observou-se que o funcionamento do sistema familiar estava alinhado para fornecer assistência direta aos membros mais jovens que estavam, ainda, desenvolvendo suas escolhas profissionais. Os relatos demonstraram a apreensão dos pais em relação ao futuro dos filhos, os quais permaneciam dependentes e morando na residência da família. Este aspecto reflete a discussão sobre o fenômeno dos "pais estendidos" apresentada por Cerveny e Berthoud (1997), denotando que, na contemporaneidade, embora os filhos estejam criados, é comum que estes permaneçam carecendo do amparo financeiro e emocional de seus pais.

Cabe evidenciar que uma participante expressou não se sentir "confortável" em estar aposentada em decorrência da significativa dependência que os seus filhos ainda possuíam. Nesse sentido, questiona-se em que medida as demandas dos filhos são capazes de influenciar na adaptação e satisfação dos pais com sua aposentadoria. Para tanto, alerta-se que tal processo é gerador de estresse no contexto da família, pois pode acarretar que o tempo livre do trabalho seja empregado em ações voltadas para atender as necessidades dos filhos.
Por outro lado, foi possível analisar que quando os filhos estavam inseridos no mercado de trabalho e contavam com maiores condições econômicas e emocionais para administrar suas vidas, a relação parental estava direcionada mais ao cuidado e à convivência do que para atender as obrigações econômicas. Nesses casos, os filhos já haviam conquistado autonomia de suas famílias de origem. Assim, é estabelecido um relacionamento mais maduro com os progenitores, baseado na liberdade e na orientação, conforme propõe McCullough e Rutenberg (1995).

Considerando o exposto nesta categoria, averiguouse que a aposentadoria ocasiona desdobramentos no contexto familiar e que estes afetam a todos os seus membros. Este evento configura-se como estressor no ciclo de vida da família, pois a sua iminência gera novas demandas para serem enfrentadas, as quais precipitam o ajustamento da estrutura e do funcionamento de todo o sistema. Ademais, ficou evidente que as crenças culturais machistas e patriarcais ainda estão presentes nas relações conjugais, circunscrevendo espaços e funções a serem desempenhados por homens e mulheres. Todavia, com a efetivação da aposentadoria é possível que esses valores sejam questionados e o ajustamento da dinâmica relacional familiar comporte um maior equilíbrio na divisão de tarefas entre os cônjuges.

A nova condição de vida altera os papéis cumpridos pelos componentes da família, modificando os campos de atividade nos quais se inseriam. Percebeu-se que esse movimento ocorreu de maneira processual, visto que a rotina e os padrões comportamentais foram reformulados na medida em que cada um dos cônjuges efetivou a sua aposentadoria. Nessa linha, constatouse que a reorganização da família contou com um período de tensão e crise, exigindo a negociação do funcionamento habitual para abarcar a presença e participação de ambos os cônjuges no lar.

\section{O tensionamento do ciclo de vida familiar no processo de aposentadoria}

Esta categoria trata das novas demandas que se instalam no contexto familiar mediante a efetivação da aposentadoria. São discutidas as tarefas e funções familiares subjacentes a este período, bem como os aspectos que influenciam na adaptação à ele.

A primeira subcategoria, "As tarefas relacionadas ao ciclo de vida familiar no período da aposentadoria", evidencia as tarefas do curso de desenvolvimento individual e familiar cumpridas pelo casal. Três participantes citaram o envelhecimento e a necessidade de autocuidado. Observou-se que ocorreu a percepção da proximidade do envelhecimento e, com isso, os 
participantes passaram a pensar sobre o seu estilo de vida. Da mesma forma, esse processo promoveu a reflexão sobre as relações familiares, haja vista que, com o declínio físico, é possível que o idoso careça do apoio das gerações mais novas para cumprir algumas de suas atividades. Os participantes referiram diversas mudanças em suas rotinas, as quais foram efetivadas mediante a demanda de atenção e cuidado consigo. Dados semelhantes também foram discutidos nos estudos de Azevedo e Carvalho (2006), Nahum-Shani e Bamberger (2011) e Szinovacz et al. (2012).

Também foram verificadas narrativas que retratam as obrigações com a geração mais velha, evidenciando que o cuidado com estes integrantes da família ocupa um espaço significativo do tempo e das atividades desenvolvidas pelos participantes. Considera-se que esta ação é uma das principais tarefas relacionadas à fase última do ciclo vital familiar, conforme apontado por Coelho (2011) e Couto et al. (2008). No entanto, observou-se que a aposentadoria foi descrita como um momento em que ampliaram-se as condições de dedicação aos membros idosos da família, uma vez que após a sua efetivação os indivíduos estavam mais liberados para tal. Ressalta-se que estes relatos foram realizados pelas participantes mulheres, as quais assumiram as responsabilidades de cuidado com os componentes da família extensa, tais como pais e sogros. Tal situação corrobora o que foi mencionado por Walsh (1995) sobre as mulheres, tradicionalmente, receberem a incumbência de cuidadoras dos membros idosos da família, o que pode ocasionar sobrecarga de funções e estresse.

Outra tarefa do ciclo de vida, apontada por quatro participantes, se refere a oferecer apoio aos filhos. Constatou-se que, embora os filhos estivessem crescidos, os progenitores permaneciam preocupados com a sua formação, atentos e respondendo às suas demandas. Foram visualizados posicionamentos nos quais o apoio se dava através da escuta, do contato telefônico e da visita esporádica. Já em outros casos, os pais utilizavam seu tempo para cumprir atividades dos filhos, os quais, devido estarem trabalhando, não conseguiam, por exemplo, acompanhar a reforma do próprio apartamento. Este aspecto relaciona-se às questões do ciclo de vida que ambos estavam tentando enfrentar e manejar: os pais dispondo de tempo livre e sendo provocados a lidar com esse fator, que se configura como algo novo e desafiador; os filhos, por sua vez, estavam em processo de emancipação e, como adultos, tendo que gerir suas vidas e desempenhar funções no contexto do trabalho e além dele.

Enfatiza-se que a relação entre pais e filhos na aposentadoria pode ter características de solidariedade e ajuda, especialmente, pelo fato dos progenitores contarem com maior autonomia para realizar certas atividades. No entanto, problematiza-se esta questão, pois, ao assumir os compromissos dos filhos, é possível que o aposentado passe a superfuncionar para tratar das responsabilidades de outros membros da família, deixando de usufruir o tempo livre de que dispõe. Essa ação pode ser utilizada, ainda, como estratégia para não ter que lidar com as demandas de ordem pessoal, conjugal e social que podem estar interpostas.

$\mathrm{Na}$ segunda subcategoria "As funções desempenhadas pela família na aposentadoria", são abordadas as vivências dos aposentados no contexto familiar, as quais se traduzem importantes na adaptação a este período. Oito participantes salientaram que a acolhida e o apoio da família foram aspectos fundamentais do processo. Averiguou-se que o contexto familiar ocupa um lugar central na vida do aposentado e é uma das suas principais referências e espaços de pertencimento neste período. Este elemento reitera que a aposentadoria é um período oportuno para o indivíduo resgatar seus vínculos familiares e, assim, construir novos sentidos para estes, conforme já foi constatado em diversos estudos (Duarte \& Melo-Silva, 2009; França, 2009; França et al., 2012; Zanelli et al., 2010).

Sobre a questão da acolhida, é importante dizer que já havia sido mencionada por Walsh (1995), haja vista que a incorporação do aposentado na família é uma das principais tarefas do casal nesta etapa da vida. Nesse sentido, a reflexão que se apresenta diz respeito às contingências do contexto familiar que irão delimitar as condições para que ocorra esse acolhimento do aposentado. Isto é, o modo como esse processo será vivenciado se relaciona diretamente à qualidade dos vínculos presentes na dinâmica relacional da família, sendo possível que, em virtude de excessivas demandas ou expectativas, emerjam dificuldades e/ou conflitos.

Outra função apontada por três participantes retratou um posicionamento no qual a esposa "prepara o terreno" para a aposentadoria do marido, intermediando o contato deste com a família e a sociedade. O conteúdo dessas narrativas indicava como justificativa que as mulheres, diferentemente dos homens, teriam mais facilidade de construir laços e permanecerem ampliando suas atividades e redes após a aposentadoria. Isto pode estar associado ao fato de que, na aposentadoria, acontecem mudanças e, consequentemente, rupturas na rede de relações sociais dos indivíduos, cujo movimento correlacionado é atribuir maior ênfase ao relacionamento familiar, conforme indicado nas pesquisas desenvolvidas por Azevedo e Carvalho (2006) e França et al. (2012). 
Considera-se que o fato das esposas assumirem a função de organizar a vida do aposentado, pode estar interligado à forma como o vínculo conjugal está estabelecido, pois a dinâmica dessa relação interfere para que a tomada de decisão possa acontecer ou ser cerceada. Esse posicionamento pode influenciar a concepção de quem é o aposentado e quais são as condições que os homens possuem para se adaptar à nova realidade de vida. Isso porque reforça a ideia do homem como sendo o provedor da família e tendo dificuldades de se inserir em contextos além do trabalho, conforme discutido por Rodrigues (2001). Percebe-se que, nessa situação, a autonomia de ambos os cônjuges pode ficar significativamente restrita, uma vez que a relação se firma sob uma dependência emocional que influencia a ação individual.

Este dado precisa ser analisado, também, à luz das regras previdenciárias vigentes no país, pois, em decorrência destas, as mulheres se aposentam antes que os homens. Questiona-se em que medida o posicionamento da esposa que "prepara o terreno" é influenciado pelos significados etimológicos da aposentadoria ("retorno ao lar") e, portanto, resulta de expectativas advindas da sociedade sobre as mulheres assumirem o cuidado do homens aposentados.

A terceira subcategoria, denominada "Aspectos que interferem na adaptação à aposentadoria", aborda as situações e as vivências que influenciaram a dinâmica das relações familiares no processo de aposentadoria. Três participantes consideraram importante o envolvimento do aposentado com a família, ou seja, que o indivíduo deve manter um posicionamento ativo, sendo este um fator que facilita sua acolhida e participação no ambiente familiar. Constatou-se que a percepção dos demais membros da família tornase relevante para o aposentado pensar sobre sua nova condição de vida e sentir-se pertencente a este grupo. Assim, evidencia-se que o indivíduo é um ser relacional, essencialmente ativo e reativo ao contexto no qual está inserido (Minuchin, 1982).

De acordo com quatro participantes, falar sobre a aposentadoria com os membros da família, constituise um aspecto facilitador no processo de adaptação. As narrativas mostraram que este posicionamento caracterizou-se como uma maneira bem sucedida de abordar o assunto entre os cônjuges e deles com seus filhos. Além do mais, isto possibilitou o compartilhamento de ideias e perspectivas relacionadas à esse período da vida, a partir do qual os integrantes da família se sentiram incluídos na vivência que o aposentado estava experimentando. Verifica-se que esse mecanismo pode apresentar-se efetivo para uma melhor compreensão do tema por parte da família e, também, para a negociação da nova rotina de vida. Watzlawick, Beavin e Jackson (2011) postularam que as pessoas estão sempre comunicando e que a transmissão de informações auxilia na organização dos eventos na família, ou seja, que a comunicação auxilia na acomodação das mudanças. Através de uma comunicação direta, as dificuldades decorrentes do processo de adaptação à aposentadoria podem ser tratadas abertamente entre os integrantes deste grupo, sendo este um exercício a ser provocado e aprimorado nas atividades que visam a orientação para aposentadoria.

A espiritualidade foi citada por seis participantes, como sendo um elemento importante e que proporciona a orientação para a família lidar com os ajustamentos que se fazem necessários neste período. Os relatos destacaram que a espiritualidade é um ponto de referência e apoio para o enfrentamento das dificuldades relacionadas ao desenvolvimento individual e familiar. Assim, analisa-se que este elemento configura-se como uma peça chave para a potencialização da resiliência na família, facilitando o enfrentamento das situações estressantes do desenvolvimento humano, conforme apontado por Walsh (2005).

Por fim, dois participantes destacaram que a assistência financeira às pessoas da família extensa também é um fator que interfere na vivência da aposentadoria. Este achado permitiu identificar que os membros da família extensa, tais como irmãos, cunhados e sogros podem manifestar demandas, especialmente, de origem econômica, cujas decorrências restringem a execução dos projetos estabelecidos para a aposentadoria. Por essa via, verifica-se a necessidade de uma análise ampla do aglomerado familiar para o entendimento das repercussões da aposentadoria. Conforme propõe Carter e McGoldrick (1995), a família é um sistema emocional que não se reduz ao grupo nuclear, mas envolve uma história intergeracional e, em cada momento do desenvolvimento, sofre a influência de relacionamentos passados e atuais.

O conjunto de dados discutidos nesta categoria revelou a interconexão entre aspectos individuais e do contexto familiar na vivência da aposentadoria. Identificou-se que nessa etapa do ciclo de vida o indivíduo está lidando com mudanças subjetivas, tais como a proximidade do envelhecimento e a busca por um maior autocuidado, e a estas se somam as demandas advindas da família nuclear e extensa, o que pode gerar sobrecarga de funções. Portanto, ao considerar estes aspectos, é possível inferir que o tensionamento do ciclo de vida congrega a mudança de status nos relacionamentos e nos papéis desempenhados na trama das relações estabelecidas numa perspectiva intergeracional. 


\section{CONSIDERAÇÕES FINAIS}

A partir dos dados apresentados e respondendo os objetivos deste estudo, destaca-se a importância da família no processo de aposentadoria, visto que o relacionamento familiar ocupa um espaço singular na vida do aposentado. As características desse contexto, tais como a qualidade dos vínculos nele estabelecidos e as condições de acolhida e apoio manifestado pelos demais integrantes do grupo, configuram-se como elementos estruturantes das ações e projetos que serão executados pelo aposentado nesse período da vida. Assim, é possível constatar que a família é um fator que influencia diretamente no processo de aposentadoria e que necessita ser devidamente considerado na apreensão do tema.

Em relação ao método de pesquisa, ressalta-se que a abordagem qualitativa permitiu a aproximação com a realidade vivenciada pelos participantes do estudo, tornando possível o reconhecimento de peculiaridades da história e do contexto familiar nos quais se inscrevem suas experiências de aposentadoria. Por esse motivo, a análise dos sistemas contextuais envolvidos no objeto de estudo redimensionou a sua compreensão, permitindo o reconhecimento de elementos que interagem e se modificam constantemente.

Como limitações do estudo, apontam-se as características socioeconômicas dos participantes, os quais pertenciam a um nível econômico que variou entre as classes sociais média e média alta. Compreende-se que a aposentadoria é um fenômeno que se apresenta de maneira diferenciada de acordo com o extrato socioeconômico do indivíduo. Diante disto, sugere-se que novos estudos sobre esta temática específica sejam desenvolvidos levando-se em conta outras realidades, pois a organização da família adquire diferentes nuances em virtude das condições socioeconômicas.

Em termos de contribuição para a prática, acreditase que este estudo favorece, sobretudo, a ampliação do conhecimento em torno da interface entre aposentadoria e família. Os dados podem subsidiar intervenções em diferentes contextos como, por exemplo, na clínica, por meio do atendimento às famílias nesse estágio do ciclo de vida, e nas organizações de trabalho, através dos programas de orientação para aposentadoria. Inclusive, reitera-se que tais programas devem envolver a participação dos familiares para que haja o intercâmbio de ideias e a coconstrução de estratégias de enfrentamento.

Por fim, enfatiza-se que os achados desta pesquisa revelam que ao considerar apenas a dimensão individual envolvida na compreensão da aposentadoria, deixase de contemplar uma série de questões familiares e sociais que influenciam decididamente na vivência desse fenômeno. Tais dados permitem visualizar, portanto, um campo fértil para a investigação e a intervenção. Assim, é relevante que novos estudos deem continuidade a esta análise e possam aprofundar, dentre outros aspectos: a) as repercussões da aposentadoria sob a perspectiva de outros membros da família, entre os quais está o sistema fraternal/filhos; b) o entendimento desse fenômeno em famílias com diferentes configurações; c) as implicações das construções socioculturais, que diferenciam os papéis de gênero, no processo de aposentadoria no contexto familiar.

\section{REFERÊNCIAS}

Amazonas, M. C. L. A., Vieira, L. L. F., \& Pinto, V. C. (2011). Modos de subjetivação femininos, família e trabalho. Psicologia: Ciência e Profissão, 31(2), 314-327. http://dx.doi.org/10.1590/S1414-98932011000200009

Andolfi, M. (2003). Manual de psicología relacional: la dimension familiar. Colombia: La Sillueta Ediciones.

Antunes, M. H. \& Moré, C. L. O. O. (2014). Família, trabalho e aposentadoria: uma revisão da produção científica no cenário brasileiro. Contextos Clínicos, 7(2), 145-154. http://dx.doi.org/10.4013/ctc.2014.72.03

Azevedo, R. P. C., \& Carvalho, A. M. (2006). O lugar da família na rede social do lazer após a aposentadoria. Revista brasileira de crescimento e desenvolvimento humano, 16(3), 76-82.

Brasil, C. N. S. (1996). Resolução $n^{\circ}$ 196, de 10 de outubro de 1996. Retrieved from: 24 maio 2012, <https://www. conselho.saude.gov.br/resolucoes/1996/reso196.doc>.

Carter, B., \& McGoldrick, M. (1995). As mudanças no ciclo de vida familiar: uma estrutura para terapia familiar ( $2^{\mathrm{a}}$ ed.). Porto Alegre: Artes Médicas.

Cerveny, C. M. O. (2011). Considerações sobre nossa visita ao ciclo vital. In C. M. O. Cerveny \& C. M. E. Berthoud (Eds.). Visitando a família ao longo do ciclo vital (pp. 161-169). São Paulo: Casa do Psicólogo.

Cerveny, C. M. O. \& Berthoud, C. M. E. (1997). Família e Ciclo Vital: nossa realidade em pesquisa. São Paulo: Casa do Psicólogo.

Coelho, M. R. M. V. P. (2011). Visitando a fase última. In C. M. O. Cerveny \& C. M. E. Berthoud. Visitando a família ao longo do ciclo vital (pp. 127-160). São Paulo: Casa do Psicólogo. 
Couto, M. C. P. P., Prati, L. E., Falcão, D. V. S., \& Koller, S. H. (2008). Terapia Familiar Sistêmica e idosos: contribuições e desafios. Revista de Psicologia Clínica, 20(1), 135-162. http://dx.doi.org/10.1590/S0103-56652008000100009

Denton, F. T. \& Spencer, B. G. (2009). What is retirement? A review and assessment of alternative concepts and measures. Canadian Journal on Aging, 28(1), 63-76. http://dx.doi.org/10.1017/S0714980809090047

Denzin, N. K. \& Lincoln, Y. S. (2000). Handbook of qualitative research. Thousand Oaks: Sage.

Duarte, C. M. \& Melo-Silva, L. L. (2009). Expectativas diante da aposentadoria: um estudo de acompanhamento em momento de transição. Revista Brasileira de Orientação Profissional, 10(1), 45-54.

França, L. H. F. P. (2009). Influências sociais nas atitudes dos 'Top' executivos em face da aposentadoria: um estudo transcultural. Revista de Administração contemporânea, 13(1), 17-35. http://dx.doi.org/10.1590/S141565552009000100003

França, L. H. F. P., Menezes, G. S., \& Siqueira, A. R. (2012). Planejamento para aposentadoria: a visão dos garis. Revista brasileira de geriatria e gerontologia, 15(4), 733-745. http://dx.doi.org/10.1590/S1809-98232012000400012

França, L. H. F. P., Menezes, G. S., Bendassolli, P. F., \& Macedo, L. S. S. (2013). Aposentar-se ou continuar trabalhando? O que influencia essa decisão? Psicologia: Ciência e Profissão, 33(3), 548-563. http://dx.doi.org/10.1590/S141498932013000300004

IBGE - Instituto Brasileiro de Geografia e Estatística (2011). Censo Demográfico 2010: resultados preliminares da amostra. Retrivied from: 10 maio 2012, <ftp://ftp.ibge.gov.br/Censos/Censo_Demografico_2010/Resultados_Pre liminares_Amostra/t abelas_de_resultados.zip>.

Johnson, R. W. (2009). Family, Public Policy, and Retirement Decisions: Introduction to the Special Issue. Research on Aging, 31(2), 139- 152. http://dx.doi.org/10.1177/0164027508328307

Magalhães, M. O., Krieger, D. V., Vivian, A. G., Straliotto, M. C. S., \& Poeta, M. P. (2004). Padrões de ajustamento na aposentadoria. Aletheia, 19, 57-68.

McCullough, P. \& Rutenberg, S. (1995). Lançando os filhos e seguindo em frente. In B. Carter \& M. McGoldrick. As mudanças no ciclo de vida familiar: uma estrutura para terapia familiar (pp. 248-268). Porto Alegre: Artes Médicas.

Minuchin, S. (1982). Famílias: funcionamento \& tratamento. Porto Alegre: Artes Médicas.

Nahum-Shani, I. \& Bamberger, P. A. (2011). Work hours, retirement, and supportive relations among older adults. Journal of Organizational Behavior, 32(1), 345-369. http://dx.doi.org/10.1002/job.662

Oliveira, A. L. \& Cerveny, C. M. O. (2011). Visitando a família madura. In C. M. O., Cerveny \& C. M. E., Berthoud. Visitando a família ao longo do ciclo vital (pp. 85-126). São Paulo: Casa do Psicólogo.

Rodrigues, C. L. (2001). Homem de pijama: o imaginário masculino em relação à aposentadoria. Revista Kairós, $4(2), 69-82$.

Soares, D. H. P., Costa, A. B., Rosa, A. M., \& Oliveira, M. L. (2007). Aposenta-Ação: Programa de Preparação para Aposentadoria. Revista Estudos Interdisciplinares sobre o Envelhecimento, 12, 143-161.

Strauss, A. \& Corbin, K. (2008). Pesquisa Qualitativa: técnicas e procedimentos para o desenvolvimento de teoria fundamentada. Porto Alegre: Artmed.

Szinovacz, M. E. (2003). Contexts and pathways: Retirement as institution, process, and experience. In G. E. Adams \& T. A. Beehr (Eds.). Retirement: Reasons, processes and outcomes (pp. 6-52). New York: Springer.

Szinovacz, M. E., Ekerdt, D. J., Butt, A., Barton, K., \& Oala, C. R. (2012). Families and Retirement. In R. Blieszner \& V. H. Bedford (Eds.). Handbook of families and aging (pp. 461-488). Califórnia: ABC-CLIO LLC.

Walsh, F. (1995). A família no estágio tardio da vida. In B. Carter \& M. McGoldrick. As mudanças no ciclo de vida familiar: uma estrutura para terapia familiar (pp. 269-290). Porto Alegre: Artes Médicas.

Walsh, F. (2005). Fortalecendo a resiliencia familiar. São Paulo: Roca.

Watzlawick, P., Beavin, J. H., \& Jackson, D. D. (2011). Pragmática da comunicação humana (18a ed.). São Paulo: Cultrix.

Zanelli, J. C. (2012). Processos Psicossociais, bem-estar e estresse na aposentadoria. Revista Psicologia: Organizações e Trabalho, 12(3), 329-340.

Zanelli, J. C., Silva, N., \& Soares, D. H. P. (2010). Orientação para aposentadoria nas organizações de trabalho: construção de projetos para o pós-carreira. Porto Alegre: Artmed.

Autores:

Marcos Henrique Antunes - Mestre, Universidade Federal de Santa Catarina

Dulce Helena Penna Soares - Doutora, Universidade Federal de Santa Catarina

CARMEN LEONTINA OJEDA OCAMPO MORÉ - Doutora, Universidade Federal de Santa Catarina

Endereço para correspondência:

Rua Capitão Romualdo de Barros, 611, apto 502 - Bairro Carvoeira

CEP 99840-600 Florianópolis, SC, Brasil

E-mail: marcos.antunes@live.com 